http://jmscr.igmpublication.org/home/

ISSN (e)-2347-176x ISSN (p) 2455-0450

crossref DOI: https://dx.doi.org/10.18535/jmscr/v9i11.28

Journal Of Medical Science And Clinical Research

\title{
A Cadaveric Study on the Anatomic Variations of the Musculocutaneous Nerve in the Infraclavicular Part of the Brachial Plexus
}

\author{
Authors \\ Dr Vidhya $B^{1}$, Dr Umarani $S^{2}$, Dr Ananthi $V^{3}$, Dr Santhakumar $\mathbf{R}^{4}$, \\ Dr Sujitha Jacinth $\mathbf{J}^{5}$, Dr Karthikeyan $\mathrm{A}^{6}$ \\ ${ }^{1,6}$ PG Student, Department of Anatomy, Rajah Muthiah Medical College and Hospital, Chidambaram \\ ${ }^{2,4,5}$ Associate Professor, Department of Anatomy, Rajah Muthiah Medical College and Hospital, \\ Chidambaram \\ ${ }^{3}$ Tutor, Department of Anatomy, Rajah Muthiah Medical College and Hospital, Chidambaram
}

\begin{abstract}
Brachial plexus begins from ventral rami of C5 to T1 segment of spinal cord. Brachial plexus has 3 cords-medial, lateral \& posterior. The Musculocutaneous nerve arises from the lateral cord of the brachial plexus, passes inferolaterally and then pierces through the coracobrachialis ${ }^{8}$ and it descends between the biceps and the brachialis, sending branches to both and continues as the lateral cutaneous nerve of the forearm ${ }^{6}$. The musculocutaneous nerve is responsible for the innervation of the flexor musculature of the elbow and the skin sensitivity from elbow to wrist $t^{15}$. Musculocutaneous nerve shows wide variations which can have clinical and surgical importance ${ }^{8}$. Present variation was observed during routine dissection on cadavers in the department of anatomy, Rajah muthiah medical college, Chidambaram. In the present study out of 50 upper extremities, $4 \%$ of musculocutaneous nerve did not pierce the coracobrachialis muscle on the right side and $4 \%$ of musculocutaneous nerve did not pierce the coracobrachialis muscle bilaterally and gave separate branch. $2 \%$ had a communicating nerve between the medial nerve and the musculocutaneous nerve after piercing coarcobrachial's muscle.2\% had no musculocutaneous nerve.
\end{abstract}

\section{Introduction}

The brachial plexus is formed by the ventral rami of the lower four cervical nerves and by the first thoracic nerve, and it supplies the upper limbs. C5, C6, C7, C8 and T1 roots unite to form trunks (upper, middle, and lower) that divide into anterior and posterior divisions. The anterior divisions of the upper and middle trunks unite to form the lateral cord, which lies laterally to the axillary artery. The musculocutaneous nerve is a continuation of the lateral cord and leaves the axilla by piercing the coracobrachialis muscle. It supplies all of the muscles of the anterior compartment of the arm and continues as a lateral cutaneous nerve of the forearm. The median nerve is formed by two roots; the medial root of the median nerve from the medial cord, and the lateral root of the median nerve from the lateral cord. Both roots join to form the median nerve in front of the third part of the axillary artery. In the literature, various anatomical variations were described by many authors. The knowledge regarding these variations can serve as a useful guide for surgeons operating in the axilla and in the $\operatorname{arm}^{9}$. 


\section{Material and Methods}

A variation in the course of musculocutaneous nerve was observed during routine dissection of 25 embalmed cadaver in department of Anatomy, Rajah muthiah Medical College and hospital, Annamalai University, Chidambaram during the study period of 3 years.

The pectoral region, the axilla and the arm were dissected. The cords and branches of the infraclavicular part of brachial plexus were dissected. The variations of the musculocutaneous nerve were noted.

\section{Observation}

Out of 50 upper extremities, in 2 extremities, musculocutaneous nerve did not pierce the coracobrachialis muscle unilaterally on right side. Butfurther courses were normal.

In the $2^{\text {nd }}$ specimen musculocutaneous nerve did not pierce the coracobrachialis muscle bilaterally (figure 1) and coarcobrachialis is supplied by direct branch from the lateral cord. A Separate branch arose from the musculocutaneous nerve to the biceps at the level of insertion of coracobrachialis muscle. After some course, separate branch to brachialis is seen and continued as a lateral cutaneous nerve of forearm. Here the original course of musculocutaneous nerve was missing.

In $3^{\text {rd }}$ specimen a communicating nerve between the medial nerve and the musculocutaneous nerve after piercing coracobrachialis muscle on left side is noted (Figure 2). And on right side, lateral cord and its components pierces the coracobrachialis muscle(Figure 4).After piercing, it continued as a lateral root of median nerve and it joined with median root of median nerve and form median nerve at the level of insertion of coracobrachialis muscle. Just before the formation of median nerve, lateral root of median nerve gave a separate branch to the biceps. After some course of median nerve, a branch from the median nerve (figure 3) arose lateral to it and ran as a muscular branch to brachialis muscle and continued as a lateral cutaneous nerve of forearm.

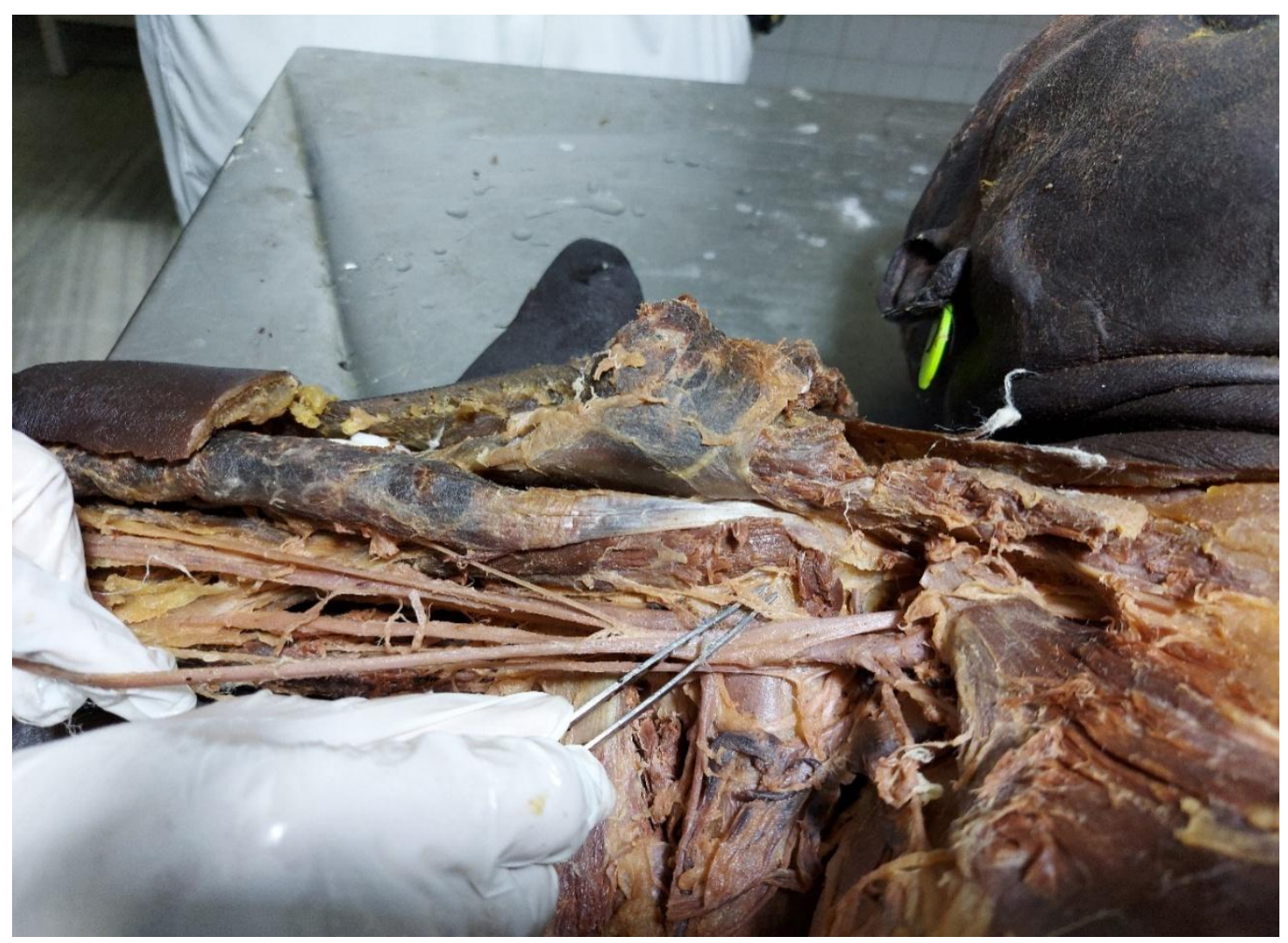

Figure 1: Non piercing coracobrachialis muscle and separate branch to biceps. Branch from lateral cord to coracobrachialis. 


\section{JMSCR Vol||09||Issue||11||Page 143-148||November}

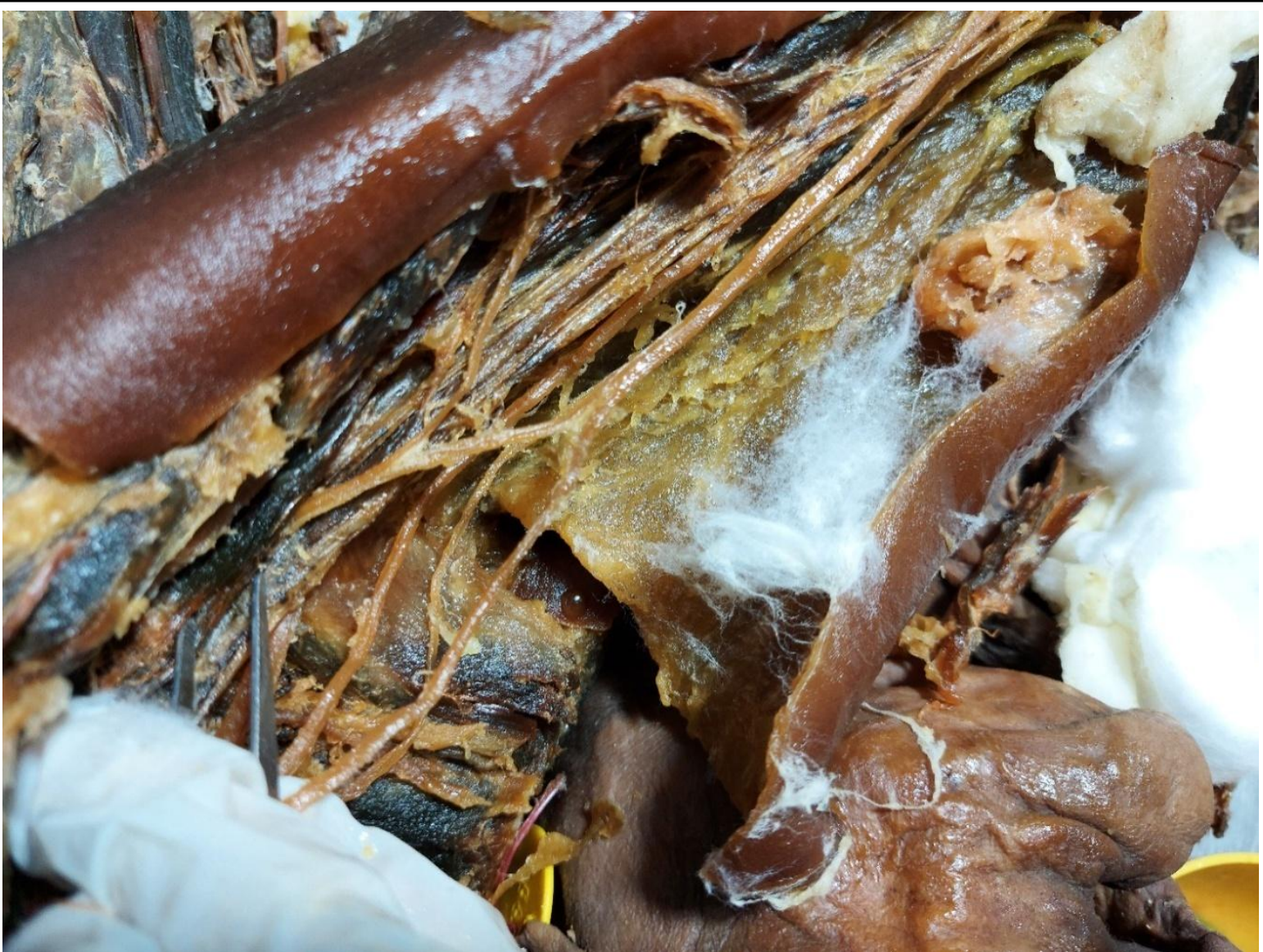

Figure 2: A communication nerve between musculocutaneous nerve and median nerve

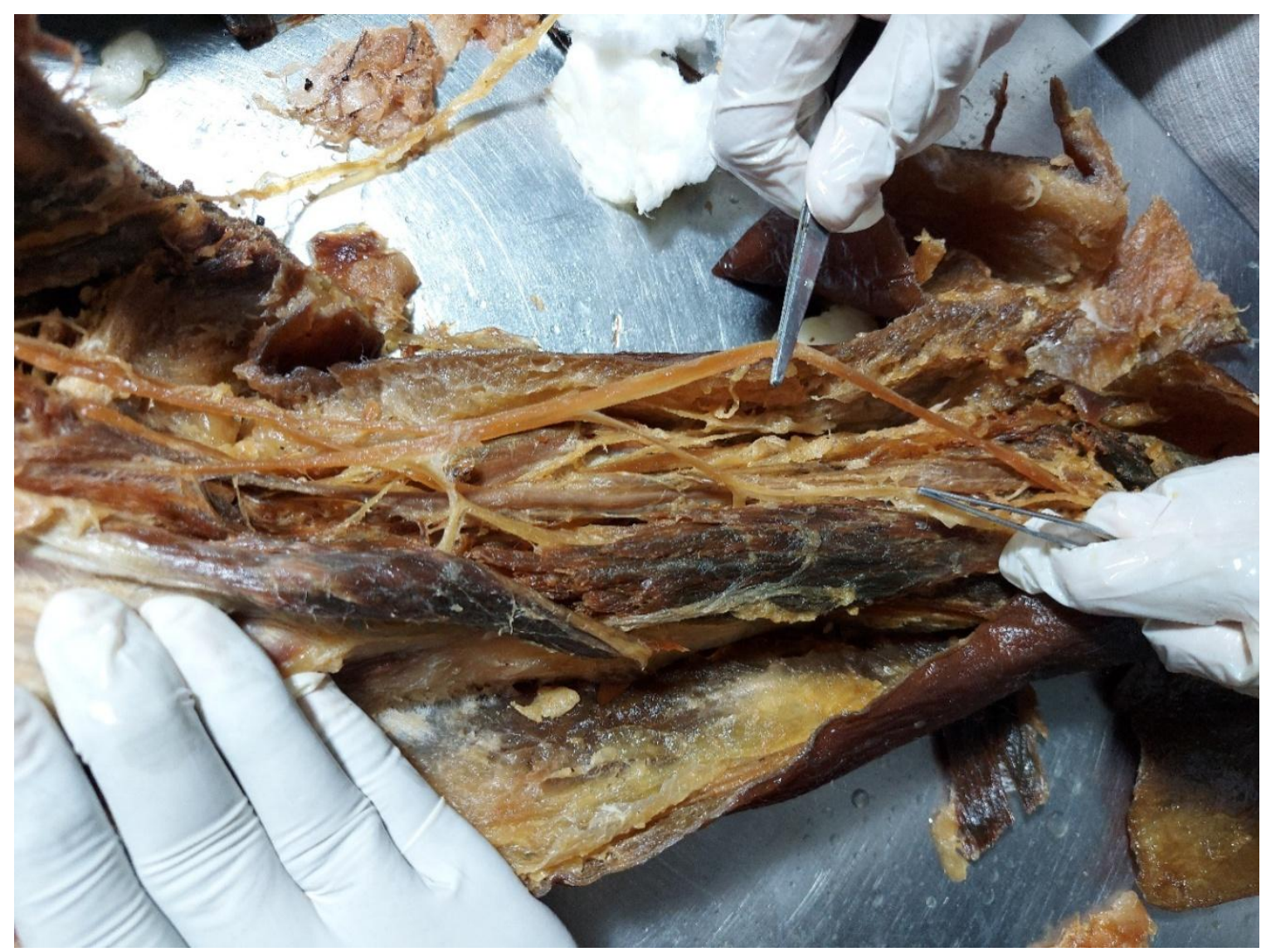

Figure 3: Absence of musculocutaneous nerve. Median nerve giving branches to anterior compartments of arm 


\section{JMSCR VoI||09||Issue||11||Page 143-148||November}

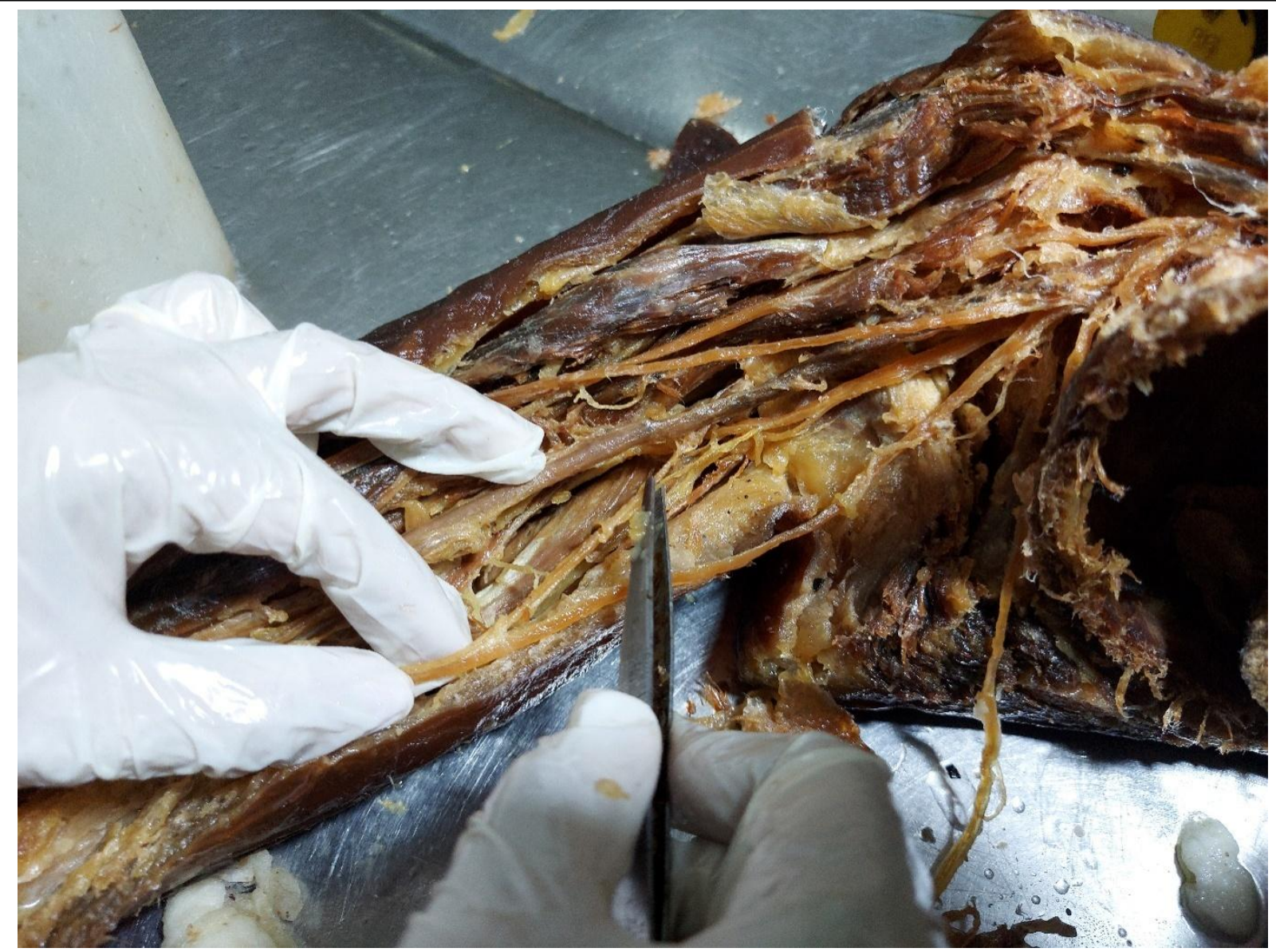

Figure 4: lateral cord pierces the coracobrachialis and continue as a lateral root of median nerve

\section{Discussion}

The musculocutaneous nerve (C4-C6), a mixed peripheral nerve, arising from the lateral cord of the brachial plexus in the axilla, usually innervates the muscles of the anterior compartment of the arm and then continues as the lateral cutaneous nerve of the forearm ${ }^{16}$. There is a variation described by a standard text book (Holinshed), in which the musculocutaneous nerve does not pierce the coracobrachialis, but splits in to two parts, one part going superficial to the muscle and the other through the muscle ${ }^{4}$. In our present study musculocutaneous nerve did not pierce coarcobrachialis muscle unilaterally (figure 1) in 2 limbs on right side and bilaterally in 4 limbs [2 cadavers]. Out of 2, one cadaver had a separate branch to biceps, brachialis. Here coracobrachialis muscle is supplied by direct branch from lateral cord.

Nayak reported that in one limb, the musculocutaneous nerve had a low origin and that the nerve was found to not pierce the coracobrachialis muscle ${ }^{12}$. In a study by Patel, instead of the whole trunk of the nerve piercing the coracobrachialis muscle, only its muscular branch or only its cutaneous branch was found to pierce the muscle. Instead of penetrating the coracobrachialis muscle, the nerve may pass behind it or between it and the short head of the biceps muscle. Occasionally, the nerve perforates not only the coracobrachialis muscle, but also the brachialis or the short head of the biceps muscle ${ }^{13}$. Like these variations in the present study we had separate branch to the coracobrachialis muscle from musculocutaneous nerve without piercing it (figure 2).

Prasada rao reported the complete absence of the musculocutaneous nerve in 2 limbs ${ }^{14}$ which partly coincides with our present study of absence of musculocutaneous nerve unilaterally (figure 3).

Ihunwo et al reported a case of the bilateral absence of the musculocutaneous nerve from the lateral cord of the brachial plexus, with four branches arising from the lateral side of the 
median nerve ${ }^{5}$. This report was in discrepancy with that of the present study, where there was only unilateral absence of the musculocutaneous nerve in one case (figure 3 ).

Nakatani et al and Le Minor observed the musculocutaneous nerve to be absent on the left side $^{11}$, which varies with the findings from two of our study cases, where the nerve was found to be absent on the right side.

Jamuna $\mathrm{M}$ et al reported musculocutaneous nerve re-joining median nerve after piercing coarcobrachialis ${ }^{6}$. In $3^{\text {rd }}$ specimen the musculocutaneous nerve was found to rejoin the median nerve after piercing the coracobrachialis and after giving off the lateral cutaneous nerve of the forearm (figure 3). The musculocutaneous nerve, after piercing the coracobrachialis, rejoined the median nerve in one case which was reported by $\mathrm{Joshi}^{7}$ and in $3.125 \%$ of the cases reported by Bhattaria ${ }^{3}$.

The variations in the course and innervations of the nerve are due to developmental inconsistency. In humans, upper limb develops from paraxial mesoderm and axons of spinal nerve grows distally to reach muscles and skin during 5th week of intrauterine life under the influence of five Hox $\mathrm{D}$ genes. The lack of coordination between the two processes due to altered signalling leads to variation in the course and supply of the nerve ${ }^{2}$. Over or under expression of one or multiple transcription factors have been found to be responsible for the variations in the formation, relation and distribution of motor nerve fibers ${ }^{10}$.

\section{Conclusion}

Variations in musculocutaneous nerve has clinical values in post traumatic stage and in the exploratory interventions of arm for peripheral nerve repair. During shoulder surgery, it is important to identify or palpate the musculocutaneous nerve, as it is vulnerable to injury from retractors which are placed under the coracoid process. Coracoid process grafting, shoulder dislocations and frequent arthroscopies may also damage the muscle as well as the nerve ${ }^{1}$.

\section{References}

1. Abhilasha Priya, Chandni Gupta, Antony Sylvan D'souza., Cadaveric Study of Anatomical Variations in the Musculocutaneous Nerve and in the Median Nerve., Journal of Morphological Sciences Vol. 36 No. 2/2019

2. Bharti A, Vaishali MP, Makarand VA. Variations in the formation and relation of median nerve. Int $\mathbf{J}$ Anat Res. 2015; 3(3):1298-1301.

3. Bhattarai $\mathrm{C}$, Poudel PP unusual variation in musculocutaneous nerves. Kathmandu Univ Med J 2009., vol-7:408-410.

4. Henry W, Holinshed WH. The Back and Limbs. In: Anatomy for surgeons: vol.3. 3rd Ed., Philadelphia, Harper \& Row.1982; p366.

5. Ihunwo AO, Osinde SP, Mukhtar AU: Distribution of median nerve to the muscles of the anterior compartment of the arm. Cent Afr J Med 1997; 43:359-60.

6. Jamuna M.,Amudha G., A Cadaveric Study on the Anatomic Variations of the Musculocutaneous Nerve in the Infraclavicular Part of the Brachial Plexus., Journal of Clinical and Diagnostic Research. 2011 November (Suppl-1), Vol5(6): 1144-1147

7. Joshi SD, Joshi SS, Athavale SA: Hitchhiking fibers of the lateral cord of the brachial plexus in search of their destination. J Anat Soc India 2008., 57:269.

8. Jyoti, Anshu Sharma, Mahesh Sharma, Ramandeep Kaur., Variation of Musculocutaneous Nerve in Infraclavicular Part of Brachial Plexus, North States Journal of Anatomy, 2018, Vol. 3, No.1

9. Maheria PB, Chinna NG, Khubchandani PR, et al. A Study of Anatomical Variations of the musculocutaneous nerve. Int J Res Med 2013;2(02):1-4 
10. Morgan BA, Tabin C. Hox genes and growth: early and late roles in limb bud morphogenesis. Dev suppl: 1994; 181-6.

11. Nakatani T, Mizukami S, Tanaka S: Three cases of the musculocutaneous nerve not perforating the coracobrachialis muscle. Acta Anat Nippon 1997a; 72:191-4

12. Nayak S, Samuel VP, Somayaji N: Concurrent variations of the median nerve, the musculocutaneous nerve and the biceps brachii muscle. Neuroanatomy 2006; 5:302.

13. Patel SJ, Patel RK. Bhatt C et.al. Variation of musculocutaneous nerve in arm with additional muscular slip in forearm. Int. J. Anat.Physiol.2013; 2(3):20-3.

14. Prasada Rao PVV, Chaudhary SC. Absence of the musculocutaneous nerve: Two case reports. Clin Anat 2001; 14:315.

15. P.S.Chitra, M. Sobana., Anatomical study of variations of Musculocutaneous nerve., National Journal of Clinical Anatomy., vol-5(3), pg-143-147 (2016).

16. Romanes G.J. Cunningham's Textbook of Anatomy, 12th edition. Oxford University Press, London. 1991; 774-826. 